\title{
Social capital and cigarette smoking among Latinos in the United States
}

This article was published in the following Dove Press journal:

Substance Abuse and Rehabilitation

2 May 2012

Number of times this article has been viewed

\author{
Shijian Li' \\ Pilar Horner ${ }^{2}$ \\ Jorge Delva ${ }^{3}$ \\ 'School of Medicine, New York \\ University, New York, NY, USA; \\ ${ }^{2}$ School of Social Work, Julian Samora \\ Research Institute, Michigan State \\ University, East Lansing, MI, USA; \\ ${ }^{3}$ School of Social Work, University of \\ Michigan, Ann Arbor, MI, USA.
}

\begin{abstract}
This paper presents the results of analyses conducted to examine if social capital indicators were associated with current cigarette smoking and with quitting smoking among a national representative sample of Latinos living in the United States. Data are from 2540 Mexican Americans, Puerto Ricans, Cuban Americans, and Other Latinos who participated in the National Latino and Asian American Survey. A significant inverse association between neighborhood cohesion and current smoking, and a positive association with quitting smoking, were found only among Mexican Americans. No other significant associations were found except for family conflict being associated with higher odds of current smoking with Cuban Americans. Implications of these findings are discussed to unravel the differences in social capital and smoking behaviors among Latino populations.
\end{abstract}

Keywords: cigarette, smoking, quitting smoking, social capital, Latinos

\section{Introduction}

Cigarette smoking and exposure to smoking resulted in an annual average of 269,655 deaths among males and 173,940 deaths among females in the United States during 2000-2004, and the estimated annual smoking-attributable productivity losses were approximately $\$ 96.8$ billion. ${ }^{1}$ While smoking-related mortality cuts across all populations in the United States, the health impact of smoking on racial/ethnic minorities is particularly serious. ${ }^{2}$ In addition, while smoking cessation programs have achieved considerable success, recent research has found that some racial/ ethnic minorities are less likely to receive advice from health professionals to quit smoking and tend to be less likely to quit smoking successfully than non-Hispanic Whites. ${ }^{3-5}$ More specifically, compared to non-Hispanic White smokers, blacks and Latinos who smoke continue to have significantly lower odds of being asked about tobacco use, being advised to quit, or having used tobacco-cessation aids during the past year in a quit attempt. ${ }^{3,6}$ Additionally, findings from a study showed that Latinos did not experience higher rates of successful quitting than non-Hispanic Whites despite being more likely to be light and intermittent smokers. ${ }^{7}$ Moreover, racial/ ethnic minority populations have been targets of tobacco industry marketing efforts, including advertising in ethnic minority communities, sponsorships of cultural events, and funding of organizations..$^{8-10}$

Increasing the field's understanding about factors that decrease smoking habits and increase rates of quitting smoking among racial/ethnic minorities would serve to strengthen smoking intervention programs. One framework proposed by the World
Correspondence: Shijian Li

550 First Avenue - VZN, 8th Floor,

New York, NY 10016, USA

$\mathrm{Tel}+\mathrm{I} 2122630483$

Fax +I 2122634086

Email shijian.li@nyumc.org 
Health Organization draws upon social determinants to understand health behaviors, including smoking and quitting smoking behaviors. ${ }^{11}$ According to the World Health Organization's final report on social determinants of health, the high burden of illness arises in large part because of the conditions in which people are born, grow, live, work, and age, which are in turn the consequence of poor social policies and programs, unfair economic arrangements, and bad politics. ${ }^{11}$

To this end, it is proposed that understanding social determinants of smoking behaviors through the lens of social capital factors, that is, social connections and social norms may contribute to discussions of racial/ethnic minorities' smoking disparities. Recently, a growing body of empirical evidence appears to suggest that some aspects of social capital may act as significant factors in reducing smoking prevalence and increasing smoking cessation rates. ${ }^{12-14}$ For example, smoking has been found to be inversely associated with higher levels of social participation and trust, ${ }^{15}$ civic participation, ${ }^{16}$ and a higher area level of social cohesion, ${ }^{17}$ community trust, and safety. ${ }^{18}$ A recent study of low-income neighborhoods in Santiago, Chile found that people with high levels of trust in their neighbors had lower odds of smoking. ${ }^{19}$

The pathways in which social capital might affect smoking and smoking cessation include rapid diffusion of antismoking messages, increased likelihood of adopting antismoking norms, social control over smoking, increased trust in public institutions that discourage smoking, and collective action for policy changes. ${ }^{18}$ Although most of the growing literature shows a protective effect of social capital against smoking initiation and favoring quitting, its protective effects do not appear to be equivocal. Sapag et al ${ }^{19}$ pointed out that there were theoretical nuances between social capital and smoking: network ties might encourage more smoking, especially if local social norms support smoking as part of daily social interactions. Consistent with this hypothesis, Li and Delva ${ }^{20}$ found that higher levels of social contacts with family members and family conflicts were positively associated with smoking among Asian American populations, and such associations differ by gender with stronger positive associations of social contacts and smoking for women. Others found that more cohesive communities might be better at preventing the uptake of smoking through informal social control or through organized community efforts to keep out tobacco advertising. ${ }^{19}$

To the authors' knowledge, few studies have examined whether, and how, social capital may be associated with smoking among the United States Latino populations.
To contribute to reducing this gap in knowledge, this study was conducted to acquire a better understanding of how different aspects of social capital may be associated with smoking with the largest, and most rapidly growing, racial/ ethnic minority population in the United States - the Latino American population. The primary research hypotheses, informed by prior research and social capital theory, were: (1) different aspects of social capital will be differentially associated with smoking and quitting smoking, and (2) the associations between social capital and smoking behaviors will vary by ethnicity.

\section{Methods}

\section{Sample}

The study used data from the National Institute of Mental Health-funded National Latino and Asian American Study (NLAAS), a nationally representative household survey conducted between May 2002 and November 2003. Sampling and survey administration procedures are described in detail elsewhere. ${ }^{21,22}$ Briefly, the NLAAS included a nationally representative sample of individuals who met the following criteria: 18 years of age or older, self-identified as Latinos or Asian Americans, and resided in households in the 50 states and Washington DC. Trained interviewers, with linguistic and cultural backgrounds similar to those of the respondents, administered the survey face-to-face in the respondents' preferred language (English, Spanish, other). The Latino sample consisted of 2554 individuals, representing a weighted response rate of $75.5 \%$, and included 868 Mexican Americans, 495 Puerto Ricans, 577 Cuban Americans, and 614 individuals of other Latino backgrounds (Other Latinos). Individuals of other Latino backgrounds were combined because their sample sizes were too small to analyze separately.

\section{Measures}

\section{Dependent variables}

The two dependent variables for the present study were: (1) if the person was a smoker at the time of the interview (a dichotomous variable), and (2) if the person had quit smoking by the time of the interview (also a dichotomous variable). These variables were derived from a single question on cigarette smoking asked in the NLAAS on whether the individual was a current smoker, an ex-smoker, had never smoked, or if the person had only smoked a few times. For the purpose of this study, current smoking was measured as the proportion of individuals who self-reported being current smokers in the entire sample. To note the percentage of 
individuals who had quit smoking (ie, not currently smoking), the proportion of all ever-smokers who had stopped smoking were measured.

\section{Independent variables}

The term "social capital" has been viewed as a multidimensional concept and there is no universal consensus on its definition and measurement. In this study, one of the social capital theory pioneers' definition was followed: Robert Putnam's conceptualization of social capital as "social connections and the attendant norms and trust." ${ }^{.23}$ Putnam and his colleague indicated that social capital could be measured by the strength of ties among family, friends, and neighbors, in the work place, at church, in civic associations, or even in an Internet-based "virtual community." 24 Accordingly, social capital was operationalized by measuring (1) families and (2) extended social networks as well as respondents' subjective evaluations of such networks. These are described next.

\section{Family-level social capital}

The family-level social capital indicators consisted of three measures: family support, family cohesion, and family cultural conflict. The family support measure consisted of the sum of three items that assessed the extent of reliance on extended family or relatives for emotional support. Specifically, the three questions were: (1) how often they talk on the phone or get together with families or relatives, (2) how much they can rely on relatives for help with a serious problem, and (3) how much they can open up to family and talk about worries. For question (1), there were five response categories ranging from "almost every day" to "less than once a month." For question (2) and (3), there were four response categories ranging from "a lot" to "not at all." The items were reverse coded with higher scores representing more family support. Cronbach's alpha for this measure was 0.69 in this study.

The family cohesion measure consisted of the sum of three items that asked respondents how strongly they agree or disagree with the following statements: (1) family members like to spend free time with each other, (2) family members feel very close to each other, and (3) family togetherness is very important. For each question, there were four response categories: "strongly agree," "somewhat agree," "somewhat disagree," and "strongly disagree". Each item was reverse coded with higher scores representing more family cohesion. Cronbach's alpha for this measure was 0.82 in this study.

The family cultural conflict measured was derived from a subscale of the Hispanic Stress Inventory. ${ }^{25}$
It is conceptualized as the absence of social capital, an alternative way of measuring social capital. ${ }^{26}$ The five items pertaining to family cultural conflict asked respondents how frequently the following five situations had occurred to them: (1) being too close to family interfered with goals, (2) argue with family over different customs, (3) lonely and isolated due to lack of family unity, (4) family relations are less important than to people close to you, and (5) family conflict arises due to different customs or personal goals. Responses were "hardly ever or never," "sometimes," or "often" with higher scores representing more conflict. Cronbach's alpha for this measure was 0.79 in this study.

\section{Extended social capital}

Extended social networks comprised of two composite scales: friend support and neighborhood cohesion. In combination, these two measures partially represent an individual's extended social network. Similar to the measure of family support, the friend support measure consisted of the sum of three items that assessed the extent of reliance on friends for emotional support. The questions were: (1) how often they talk on the phone or get together with friends, (2) how much they can rely on friends when they have a serious problem, and (3) how much they can open up to friends and talk about worries. These items were reverse coded with higher scores representing more support from friends. Cronbach's alpha for this measure was 0.76 in this study.

The neighborhood cohesion measure, as with the existing literature, ${ }^{27,28}$ was constructed from four items that asked whether people in the neighborhood: (1) can be trusted, (2) get along with each other, (3) would help in an emergency, and (4) look out for one another. For each question there were four response categories: "very true," "somewhat true," "not very true," and "not at all true." The items were reverse coded and summed up with higher scores representing higher levels of neighborhood cohesion. Cronbach's alpha for this measure was 0.81 in this study.

\section{Covariates}

A number of covariates that prior research has found to be associated with smoking behaviors were also included. They included demographic characteristics, socioeconomic status, English language proficiency, length of residency in the United States, and everyday discrimination. The demographic characteristics were ethnicity (Mexican Americans, Puerto Ricans, Cuban Americans, and Other Latinos), age (18-24, 25-39, 40-59, and 60+ years), and gender and marital status (currently married/partnered 
versus otherwise). Socioeconomic status was measured by education levels ("less than high school: 0-11 years," "high school graduate: 12 years," and "some college, university graduate, or more: $13+$ years") and annual household income (low income $\leq \$ 14,999$, lower middle income $=\$ 15,000$ $\$ 34,999$, upper middle income $=\$ 35,000-\$ 74,999$, and high income $=\$ 75,000+$ ).

English language proficiency was assessed by three questions asking respondents' how well they speak, read, and write in English. Each question had four possible response categories (poor, fair, good, and excellent). Scores from the three items were summed and dichotomized to indicate low and high English proficiency with six as the cutoff (poor/ fair on all three items). Duration of stay in the United States was coded into three categories (born in the United States, 1-10 years, and 11+ years). Experiences of everyday discrimination have been found to be associated with substance use. ${ }^{29}$ For this reason, this variable was included in the study. The measure was derived from nine items originally used in the Detroit Area Study to measure perceptions of chronic and routine unfair treatment. ${ }^{30}$ The mean of nine items was used to measure perceptions of discrimination. Cronbach's alpha for this measure was 0.91 in this study.

\section{Analytic strategy}

The prevalence of current smoking and the percentage of ever-smokers who quit smoking were analyzed for the entire sample and for each Latino ethnic group. Similarly, descriptive statistics and bivariate statistics - chi-squared test or analysis of variance to evaluate differences in the current smoking prevalence and quitting rates among former smokers - were conducted for the entire sample and also for each Latino ethnic group. Of note, in the descriptive analysis, all social capital measures were additive scores of included items with higher scores representing higher levels of the constructs being measured. But in the multivariate regression analyses, these measures were normalized to have zero mean and a standard deviation of one in the full NLAAS Latino sample population as suggested. ${ }^{27}$

Once the bivariate relationships were examined, independent variables were entered into multiple logistic regression models to test if current smokers differed from nonsmokers and if current smokers differed from former smokers on the various dimensions of social capital, controlling for the study's covariates. In the adjusted analysis, the sample was stratified by ethnic group and separate analyses were conducted. Two-way interaction tests were also conducted between gender and the social capital indicators.
All analyses were conducted with Stata $^{\circledR}$ version 11.0 (StataCorp LP, College Station, TX) and survey design effects were taken into account with the linearized method for variance estimation due to the complex sampling design. ${ }^{31}$

\section{Results \\ Sample characteristics and smoking behaviors}

Table 1 presents the weighted variables for the entire Latino sample and for the four Latino ethnic groups. The weighted sample population included almost equal numbers of males and females with $61.6 \%$ younger than 40 years of age. The majority $(64.7 \%)$ of the population were married/partnered. About $44.1 \%$ of the population had less than 12 years of education with $31.4 \%$ reporting receiving 13 years or more of education. The population was also predominantly low-to-middle income with about $55.5 \%$ earning less than $\$ 35,000$ per year. The majority was foreign born $(57.1 \%)$, with $56.6 \%$ identifying their ethnicity as Mexican. Nearly half $(46.4 \%)$ of the weighted sample indicated their English was "poor or fair."

The sample also demonstrated substantial differences in some aspects across the ethnic groups. For example, Mexican Americans were more likely to get married (69.7\%) than Puerto Ricans (54.0\%) and other ethnic groups. The highest percentage of individuals with more than a high school education was found among Cuban Americans $(51.8 \%)$, which was more than twice that of Mexican Americans (23.2\%). In terms of income, Cuban Americans and Puerto Ricans were more likely than Mexican Americans to have a household income of more than $\$ 75,000$ dollars. As far as English proficiency, $76.7 \%$ of Puerto Ricans rated their English as good or excellent as compared to $46.9 \%$ of Mexican and $57.4 \%$ of Cuban respondents.

Also shown in Table 1 are the smoking behaviors of the Latino American populations. Overall, the current smoking prevalence among adult Latinos was estimated at $20.0 \%$, but the prevalence varied substantially by ethnicity. Specifically, Puerto Ricans had the highest prevalence of current smoking (30.7\%), while Mexican Americans had the lowest (18.1\%). Cuban Americans (22.6\%) and Other Latinos (19.4\%) were between the two extremes. There also was substantial variability in quitting smoking rates. Among all the eversmokers, Mexican Americans had the highest quitting rates (59.3\%), substantially higher than the Puerto Ricans (46.5\%) who had the lowest quitting rates.

The results of the bivariate analyses, also shown in Table 1, indicate that among the entire sample of Latinos, 
Table I Weighted sample characteristics of Latinos by national origin ( $\mathrm{N}=2554$; National Latino and Asian American Survey, 2002-2003)

\begin{tabular}{|c|c|c|c|c|c|}
\hline \multirow[b]{2}{*}{ Characteristics } & \multicolumn{5}{|c|}{ Sample N (weighted \%) ${ }^{c}$} \\
\hline & All Latinos & Mexican American & Puerto Rican & Cuban American & Other Latinos \\
\hline & $2554(100)$ & $868(56.6)$ & $495(10.1)$ & $577(4.6)$ & $614(28.7)$ \\
\hline \multicolumn{6}{|l|}{ Gender } \\
\hline Male & $1 \mid 27(51.5)^{\mathrm{a}}$ & $398(51.5)^{\mathrm{a}}$ & $213(51.5)^{\mathrm{a}}$ & $276(5 I .5)$ & $240(51.5)^{\mathrm{a}}$ \\
\hline Female & $1427(48.5)$ & $470(48.5)$ & $282(48.5)$ & $301(48.5)$ & $374(48.5)$ \\
\hline \multicolumn{6}{|l|}{ Age, years } \\
\hline $18-24$ & $403(20.7)$ & $169(20.7)$ & 81 (20.7) & $40(20.7)$ & $113(20.7)$ \\
\hline $25-39$ & 988 (40.9) & $4 I I(4 I .5)$ & $176(40.5)$ & $150(37.3)$ & $25 I(40.4)$ \\
\hline $40-59$ & $803(28.0)$ & $226(27.8)$ & $172(28.2)$ & $208(29.2)$ & $197(28.0)$ \\
\hline $60+$ & $360(10.5)^{b}$ & $62(10.0)^{\mathrm{b}}$ & $66(10.7)^{\mathrm{b}}$ & $179(12.8)$ & $53(11.0)$ \\
\hline \multicolumn{6}{|l|}{ Marital status } \\
\hline Married & I599 (64.2) & $618(69.7)$ & $27 \mid(54.0)$ & $351(60.6)$ & $359(57.5)$ \\
\hline Unmarried & $955(35.8)$ & $250(30.3)$ & $224(46.0)$ & $226(39.4)$ & $255(42.5)$ \\
\hline \multicolumn{6}{|l|}{ Education } \\
\hline $0-11$ years & $994(44.1)$ & $44 I(53 . I)$ & $172(32.6)$ & $\mid 77(2 \mid .0)$ & $204(34.2)$ \\
\hline 12 years & $633(24.5)$ & $215(23.7)$ & $140(30.1)$ & $136(27.2)$ & $142(23.6)$ \\
\hline$\geq 13$ years & $927(3 \mid .4)^{\mathrm{a}, \mathrm{b}}$ & $212(23.2)^{\mathrm{a}, \mathrm{b}}$ & $183(37.4)^{\mathrm{b}}$ & $264(5 \mid .8)$ & $268(42.3)^{\mathrm{a}, \mathrm{b}}$ \\
\hline \multicolumn{6}{|l|}{ Household income, $\$$} \\
\hline $0 / 14,999$ & $703(27.2)$ & $250(29.6)$ & 137 (25.9) & $166(21.9)$ & 150 (23.7) \\
\hline $15,000 / 34,999$ & $692(28.3)$ & $272(30.8)$ & $109(22.5)$ & $133(24.0)$ & $178(26.2)$ \\
\hline $35,000 / 74,999$ & $685(27.9)$ & $227(26.2)$ & $139(29.5)$ & |4| (25.9) & $178(30.9)$ \\
\hline $75,000+$ & $474(16.7)$ & $119(13.4)$ & $110(22.3)$ & 137 (28.2) & $108(19.3)^{\mathrm{b}}$ \\
\hline \multicolumn{6}{|l|}{ Duration of stay in US } \\
\hline US born & 924 (42.9) & $380(43.8)$ & $278(58.7)$ & $76(23.6)$ & $190(38.7)$ \\
\hline $\mathrm{I}-10$ years & $495(18.6)$ & $164(18.5)$ & $24(6.30)$ & $165(35.5)$ & $142(20.3)$ \\
\hline II+years & II $27(38.5)^{\mathrm{a}, \mathrm{b}}$ & $319(37.7)^{\mathrm{a}}$ & $192(35.0)$ & $335(40.9)$ & $28 I(4 \mid .0)^{\mathrm{a}, \mathrm{b}}$ \\
\hline \multicolumn{6}{|l|}{ English proficiency } \\
\hline Poor/fair & II $92(46.1)$ & $443(53.1)$ & $134(23.5)$ & $321(42.6)$ & $294(40.9)$ \\
\hline Excellent/good & $1353(53.9)^{\mathrm{a}}$ & $422(46.9)^{\mathrm{a}}$ & $356(76.5)$ & $255(57.4)$ & $320(59.2)$ \\
\hline Discrimination, mean (SE) & $\mathrm{I} .82(3.37)^{\mathrm{b}}$ & $\mathrm{I} .79(4.4 \mathrm{I})$ & $2.01(0.06)$ & $1.54(0.05)$ & I.85 $(0.06)^{\mathrm{b}}$ \\
\hline \multicolumn{6}{|l|}{ Social capital, mean (SE) } \\
\hline Family support & $9.60(0.08)$ & $9.63(0.11)$ & $9.63(0.12)$ & $10.44(0.2 I)$ & $9.41(0.16)$ \\
\hline Family cohesion & $10.88(0.05)$ & $10.89(0.07)$ & $10.56(0.08)$ & $11.15(0.07)$ & $10.93(0.09)$ \\
\hline Family conflict & $6.35(0.04)$ & $6.31(0.07)$ & $6.56(0.09)$ & $6.20(0.08)$ & $6.38(0.10)$ \\
\hline Friend support & $8.37(0.06)$ & $8.15(0.09)$ & $8.58(0.19)$ & $9.70(0.14)$ & $8.52(0.15)$ \\
\hline Neighborhood cohesion & $12.04(0.07)^{\mathrm{a}, \mathrm{b}}$ & $12.03(0.10)^{\mathrm{a}, \mathrm{b}}$ & $11.74(0.16)$ & I2.7| (0.23) & $12.05(0.15)$ \\
\hline \multicolumn{6}{|l|}{ Smoking behaviors } \\
\hline \% current smokers, mean (SE) & $20.0(1.19)$ & I8.1 (I.78) & $30.7(2.30)$ & $22.6(2.74)$ & $19.4(1.98)$ \\
\hline \% quitters among ever smokers, mean (SE) & $55.7(2.37)$ & $59.3(3.61)$ & $46.5(3.22)$ & $49.0(4.59)$ & $53.7(3.73)$ \\
\hline
\end{tabular}

Notes: ${ }^{a} P<0.05$ for smoking (chi-squared test); ${ }^{\mathrm{P} P}<0.05$ for quitting smoking (chi-squared test/analysis of variance); ${ }^{\mathrm{N}} \mathrm{N}$ refers to the unweighted sample, but percentage in the parenthesis is weighted.

Abbreviations: SE, standard error; US, United States.

factors related to current smoking or quitting smoking were not the same. While for both current smoking and quitting smoking, there were significant differences across education and duration of stay in the United States. Current smoking was correlated with gender and English proficiency level, and quitting smoking was correlated with age and perceived discrimination. Interestingly, neither current smoking nor quitting smoking was associated with household income for the entire sample and for three groups (Mexican Americans, Puerto Ricans, and Cuban Americans). In terms of social capital, the bivariate analysis showed only neighborhood cohesion to be significantly associated with smoking and quitting smoking in the aggregate sample and among the subsample of Mexican Americans. Social capital indicators attributable to family were not found to be related to smoking behaviors.

\section{Smoking and social capital: results of multivariate models}

Results of the multiple logistic regression analyses with current smoking as the dependent variable are shown in Table 2. Some indicators of social capital were associated with 
Table 2 Social capital differences between current smokers and noncurrent smokers by Latino ethnicity: results of weighted multivariate logistic regression analyses (National Latino and Asian American Survey, 2002-2003)

\begin{tabular}{|c|c|c|c|c|c|c|c|c|}
\hline \multirow[t]{2}{*}{ Characteristic } & \multicolumn{2}{|c|}{$\begin{array}{l}\text { Mexican American } \\
\left(\mathrm{N}^{\mathrm{a}}=796\right) \\
\end{array}$} & \multicolumn{2}{|c|}{$\begin{array}{l}\text { Puerto Rican } \\
(\mathbf{N}=46 \mathrm{I}) \\
\end{array}$} & \multicolumn{2}{|c|}{$\begin{array}{l}\text { Cuban American } \\
(\mathrm{N}=539)\end{array}$} & \multicolumn{2}{|c|}{$\begin{array}{l}\text { Other Latinos } \\
(\mathrm{N}=569) \\
\end{array}$} \\
\hline & OR & $95 \% \mathrm{Cl}$ & OR & $95 \% \mathrm{Cl}$ & OR & $95 \% \mathrm{Cl}$ & OR & $95 \% \mathrm{Cl}$ \\
\hline \multicolumn{9}{|l|}{ Social capital } \\
\hline Family support & 1.15 & $0.98-1.35$ & 1.22 & $0.8 \mathrm{I}-\mathrm{I} .84$ & 0.84 & $0.64-1.11$ & 0.91 & $0.63-1.31$ \\
\hline Family cohesion & 1.02 & $0.87-1.20$ & 1.13 & $0.78-1.62$ & 0.83 & $0.55-1.26$ & 1.01 & $0.76-1.35$ \\
\hline Family conflict & 1.09 & $0.88-1.35$ & 1.08 & $0.76-1.54$ & $1.32 *$ & $1.03-1.68^{*}$ & 1.04 & $0.75-1.44$ \\
\hline Friend support & 0.97 & $0.78-1.21$ & 0.73 & $0.53-1.02$ & 0.94 & $0.70-1.25$ & 1.05 & $0.8 \mathrm{I}-\mathrm{I} .36$ \\
\hline Neighborhood cohesion & $0.62 *$ & $0.47-0.8 I^{*}$ & 1.09 & $0.86-1.37$ & 0.86 & $0.62-1.21$ & 0.79 & $0.58-1.07$ \\
\hline \multicolumn{9}{|l|}{ Age, years } \\
\hline \multicolumn{9}{|l|}{$(r e f=18-24)$} \\
\hline 25-39 & 1.31 & $0.79-2.16$ & 1.53 & $0.55-4.28$ & 2.34 & $0.84-6.52$ & 1.26 & $0.56-2.86$ \\
\hline $40-59$ & 1.60 & $1.13-2.26$ & 1.45 & $0.63-3.31$ & 1.99 & $0.66-6.06$ & 1.18 & $0.46-2.99$ \\
\hline $60+$ & 0.57 & $0.17-1.97$ & $0.30 *$ & $0.10-0.92 *$ & 1.30 & $0.34-5.01$ & 1.64 & $0.62-4.34$ \\
\hline \multicolumn{9}{|l|}{ Gender } \\
\hline$($ ref $=$ male $)$ & $0.25 *$ & $0.15-0.43^{*}$ & 0.65 & $0.4 I-I .04$ & $0.31 *$ & $0.20-0.48^{*}$ & $0.52^{*}$ & $0.31-0.88 *$ \\
\hline \multicolumn{9}{|l|}{ Marital status } \\
\hline (ref $=$ unmarried) & 0.57 & $0.25-1.28$ & 0.74 & $0.32-1.72$ & 1.39 & $0.68-2.83$ & 1.04 & $0.60-1.81$ \\
\hline \multicolumn{9}{|l|}{ Education } \\
\hline \multicolumn{9}{|l|}{ (ref = <high school) } \\
\hline High school graduate & 0.66 & $0.32-1.35$ & 0.99 & $0.52-1.88$ & 1.32 & $0.55-3.14$ & 1.02 & $0.50-2.09$ \\
\hline College or above & $0.46^{*}$ & $0.25-0.85^{*}$ & 0.61 & $0.3|-1.2|$ & 1.03 & $0.52-2.04$ & 0.45 & $0.19-1.11$ \\
\hline \multicolumn{9}{|l|}{ Household income, $\$$} \\
\hline \multicolumn{9}{|l|}{$(r e f=<15,000)$} \\
\hline $15,000 / 34,999$ & 1.79 & $1.02-3.15$ & 0.69 & $0.25-1.96$ & 0.78 & $0.43-1.39$ & 0.68 & $0.34-1.38$ \\
\hline $35,000 / 74,999$ & 1.23 & $0.79-1.91$ & 0.66 & $0.29-1.50$ & 0.75 & $0.30-1.85$ & 0.54 & $0.20-1.41$ \\
\hline $75,000+$ & 1.09 & $0.54-2.20$ & 0.50 & $0.20-1.29$ & 0.64 & $0.23-1.83$ & 0.40 & $0.16-1.02$ \\
\hline \multicolumn{9}{|l|}{ English proficiency } \\
\hline$($ ref $=$ poor $/$ fair $)$ & 1.61 & $0.73-3.55$ & $2.03 *$ & $1.20-3.45^{*}$ & 0.57 & $0.24-1.35$ & 1.92 & $0.80-4.65$ \\
\hline \multicolumn{9}{|l|}{ Duration of stay in US } \\
\hline \multicolumn{9}{|l|}{$($ ref $=$ US born $)$} \\
\hline $1-10$ years & 0.48 & $0.16-1.38$ & 1.05 & $0.38-2.90$ & $0.30 *$ & $0.10-0.85^{*}$ & 0.58 & $0.28-1.22$ \\
\hline $\mathrm{II}+$ years & $0.34 *$ & $0.15-0.74 *$ & $0.44^{*}$ & $0.21-0.90^{*}$ & $0.26^{*}$ & $0.10-0.68^{*}$ & $0.43^{*}$ & $0.21-0.86 *$ \\
\hline Discrimination, mean & 0.83 & $0.66-1.04$ & 0.85 & $0.62-1.17$ & 0.95 & $0.57-1.58$ & $1.42 *$ & $1.09-1.85^{*}$ \\
\hline
\end{tabular}

Notes: *Indicates statistically significant odds ratios; ${ }^{\mathrm{N}} \mathrm{N}$ refers to the unweighted sample, but regression analysis is weighted. Sample sizes for each of the populations are slightly smaller than those shown in Table I due to listwise deletion of cases when conducting the analyses with all the variables entered simultaneously.

Abbreviations: $\mathrm{Cl}$, confidence interval; OR, odds ratio; ref, reference; US, United States.

current smoking for some Latino ethnic groups. Specifically, after controlling for covariates, neighborhood cohesion was significantly and inversely associated with current smoking among Mexican Americans (odds ratio $[\mathrm{OR}]=0.62 ; 95 \%$ confidence interval $[\mathrm{CI}]=0.47-0.81$ ). Family conflict was positively associated with current smoking among Cuban Americans $(\mathrm{OR}=1.32 ; 95 \% \mathrm{CI}=1.03-1.68)$. None of the other social capital indicators (ie, family support, family cohesion, and friend support), were significantly associated with current smoking.

The analyses also revealed different associations between the sociodemographic covariates and current smoking for the various Latino ethnic groups. For example, females had significantly lower odds of smoking than men among Mexican Americans $(\mathrm{OR}=0.25 ; 95 \% \mathrm{CI}=0.15-0.43)$,
Cuban Americans $(\mathrm{OR}=0.31 ; 95 \% \mathrm{CI}=0.20-0.48)$, and Other Latinos ( $\mathrm{OR}=0.52 ; 95 \% \mathrm{CI}=0.31-0.88)$. Age was not significantly associated with current smoking with the exception of Puerto Ricans 60 years and older who had lower odds of being current smokers than 18-24 year old Puerto Ricans $(\mathrm{OR}=0.30 ; 95 \% \mathrm{CI}=0.10-0.92)$. With regard to education, the only significant finding was that Mexican Americans with at least some college education had lower odds of being current smokers when compared to those without a high school education ( $\mathrm{OR}=0.46 ; 95 \%$ $\mathrm{CI}=0.25-0.85$ ). Neither household income nor marital status was associated with current smoking status across all the four Latino subgroups.

Puerto Ricans with good/excellent English skills were more likely to be current smokers than those with poor/ 
fair English $(\mathrm{OR}=2.03 ; 95 \% \mathrm{CI}=1.20-3.45)$. Living in the United States for 11 years or more was associated with significantly lower odds of current smoking when compared to those born in the United States among all four Latino ethnic groups. Finally, experience of everyday discrimination was positively associated with current smoking only among Other Latinos $(\mathrm{OR}=1.42 ; 95 \% \mathrm{CI}=1.09-1.85)$.

Results of the multiple logistic regressions with quitting smoking as the dependent variable for the four Latino ethnic groups are shown in Table 3. None of the family level social capital variables were significantly associated with quitting smoking among the four Latino ethnic groups. Puerto Ricans with greater support from friends had higher odds of being an ex-smoker ( $\mathrm{OR}=1.73 ; 95 \% \mathrm{CI}=1.22-2.46)$.
This association was not significant with the other Latino groups. Neighborhood cohesion was associated with higher odds of quitting smoking among Mexican Americans $(\mathrm{OR}=1.69 ; 95 \% \mathrm{CI}=1.23-2.31)$ and Cuban Americans $(\mathrm{OR}=1.47 ; 95 \% \mathrm{CI}=1.01-2.13)$, but with lower odds of quitting smoking among Puerto Ricans $(\mathrm{OR}=0.78 ; 95 \%$ $\mathrm{CI}=0.62-1.00$ ).

The analyses also revealed different associations between the sociodemographic covariates and quitting smoking for the various Latino ethnic groups. Mexican Americans and Puerto Ricans 60 years old or older had much higher odds of quitting smoking ( $\mathrm{OR}=6.59$ and 8.46, respectively) when compared to 18-24 year olds. Other Latinos with annual household incomes of $\$ 75,000$ or higher had higher odds of

Table 3 Social capital differences between individuals who quit smoking (among those who had ever smoked) versus those who are current smokers by Latino ethnicity: results of weighted multivariate logistic regression analyses (National Latino and Asian American Survey, 2002-2003)

\begin{tabular}{|c|c|c|c|c|c|c|c|c|}
\hline \multirow[t]{2}{*}{ Characteristic } & \multicolumn{2}{|c|}{$\begin{array}{l}\text { Mexican American } \\
\left(N^{a}=327\right)\end{array}$} & \multicolumn{2}{|c|}{$\begin{array}{l}\text { Puerto Rican } \\
(\mathbf{N}=\mathbf{2 5 8})\end{array}$} & \multicolumn{2}{|c|}{$\begin{array}{l}\text { Cuban American } \\
(N=238)\end{array}$} & \multicolumn{2}{|c|}{$\begin{array}{l}\text { Other Latinos } \\
(N=216)\end{array}$} \\
\hline & OR & $95 \% \mathrm{Cl}$ & OR & $95 \% \mathrm{Cl}$ & OR & $95 \% \mathrm{CI}$ & OR & $95 \% \mathrm{Cl}$ \\
\hline \multicolumn{9}{|l|}{ Social capital } \\
\hline Family support & 0.80 & $0.65-0.99$ & 0.75 & $0.44-1.28$ & 1.00 & $0.66-1.52$ & 0.97 & $0.61-1.54$ \\
\hline Family cohesion & 0.93 & $0.80-1.09$ & 0.79 & $0.57-I .1 \mid$ & 1.22 & $0.76-1.96$ & 0.92 & $0.59-1.42$ \\
\hline Family conflict & 0.95 & $0.7 I-I .26$ & 0.77 & $0.49-1.20$ & 0.95 & $0.63-1.45$ & 1.00 & $0.67-1.47$ \\
\hline Friend support & 1.19 & $0.88-1.60$ & $\mathrm{I} .73 *$ & $1.22-2.46^{*}$ & 1.06 & $0.68-1.65$ & 1.04 & $0.74-1.46$ \\
\hline Neighborhood cohesion & $1.69 *$ & $\mathrm{I} .23-2.3 \mathrm{I} *$ & $0.78^{*}$ & $0.62-1.00 *$ & $1.47 *$ & $1.01-2.13^{*}$ & 1.29 & $0.89-1.87$ \\
\hline \multicolumn{9}{|l|}{ Age, years } \\
\hline \multicolumn{9}{|l|}{$(r e f=18-24)$} \\
\hline $25-39$ & 1.15 & $0.60-2.21$ & 1.29 & $0.33-5.13$ & 0.55 & $0.12-2.40$ & 0.82 & $0.27-2.51$ \\
\hline $40-59$ & 1.25 & $0.62-2.51$ & 2.20 & $0.68-7.08$ & 1.30 & $0.32-5.27$ & 2.59 & $0.69-9.71$ \\
\hline $60+$ & $6.59 *$ & $\left.|.37-3| .8\right|^{*}$ & $8.46 *$ & $2.31-30.96 *$ & 2.58 & $0.58-11.44$ & 1.93 & $0.40-9.31$ \\
\hline \multicolumn{9}{|l|}{ Gender } \\
\hline$($ ref $=$ male $)$ & 1.69 & $0.87-3.30$ & 0.85 & $0.5 \mathrm{I}-\mathrm{I} .44$ & 1.50 & $0.79-2.86$ & 1.16 & $0.64-2.09$ \\
\hline \multicolumn{9}{|l|}{ Marital status } \\
\hline (ref = unmarried) & 1.84 & $0.90-3.79$ & 1.83 & $0.7 I-4.69$ & 0.82 & $0.31-2.16$ & 0.71 & $0.39-1.29$ \\
\hline \multicolumn{9}{|l|}{ Education } \\
\hline \multicolumn{9}{|l|}{ (ref $=<$ high school) } \\
\hline High school graduate & 1.30 & $0.57-2.98$ & 0.93 & $0.43-2.02$ & 1.58 & $0.55-4.55$ & 0.77 & $0.28-2.12$ \\
\hline College or above & 1.64 & $0.85-3.17$ & $1.6 \mid$ & $0.73-3.56$ & 1.82 & $0.57-5.88$ & 2.50 & $0.81-7.73$ \\
\hline \multicolumn{9}{|l|}{ Household income, \$ } \\
\hline \multicolumn{9}{|l|}{$($ ref $=<15,000)$} \\
\hline $15,000 / 34,999$ & 0.59 & $0.31-1.12$ & 1.22 & $0.45-3.29$ & 2.01 & $0.87-4.65$ & 2.36 & $0.89-6.25$ \\
\hline $35,000 / 74,999$ & 0.95 & $0.55-1.62$ & 1.53 & $0.66-3.50$ & 2.54 & $0.76-8.55$ & 1.33 & $0.43-4.11$ \\
\hline $75,000+$ & 1.02 & $0.43-2.41$ & 1.69 & $0.60-4.77$ & 1.96 & $0.64-6.01$ & $3.21 *$ & I.I8-8.74* \\
\hline \multicolumn{9}{|l|}{ English proficiency } \\
\hline$($ ref $=$ poor/fair $)$ & 0.78 & $0.28-2.19$ & 0.51 & $0.26-1.02$ & 1.00 & $0.22-4.57$ & 0.91 & $0.34-2.44$ \\
\hline \multicolumn{9}{|l|}{ Duration of stay in US } \\
\hline \multicolumn{9}{|l|}{$($ ref $=$ US born $)$} \\
\hline $1-10$ years & 3.10 & $0.95-10.14$ & 0.62 & $0.19-2.03$ & 0.43 & $0.13-1.47$ & 1.64 & $0.54-5.01$ \\
\hline $\mathrm{II}+$ years & 2.41 & $0.85-6.84$ & $2.74 *$ & $1.24-6.05^{*}$ & 0.96 & $0.38-2.42$ & 2.49 & $0.88-7.03$ \\
\hline Discrimination, mean & 1.23 & $0.94-1.62$ & 1.36 & $0.84-2.22$ & 0.96 & $0.52-1.78$ & 0.70 & $0.47-1.03$ \\
\hline
\end{tabular}

Notes: *Indicates statistically significant odds ratios; ${ }^{a} \mathrm{~N}$ refers to the unweighted sample, but regression analysis is weighted. Sample sizes for each of the populations are slightly smaller than those shown in Table I due to listwise deletion of cases when conducting the analyses with all the variables entered simultaneously. Abbreviations: $\mathrm{Cl}$, confidence interval; OR, odds ratio; ref, reference; US, United States. 
quitting smoking than those with annual incomes of under $\$ 15,000(\mathrm{OR}=3.21 ; 95 \% \mathrm{CI}=1.18-8.74)$. Income was not associated with quitting smoking for the other Latino ethnic groups. Puerto Ricans who have lived in the United States for 11 years or longer had higher odds of quitting smoking $(\mathrm{OR}=2.74 ; 95 \% \mathrm{CI}=1.24-6.05)$. Neither the level of English proficiency nor everyday discrimination was associated with quitting smoking.

Two-way interactions between gender and the social capital variables were tested for both dependent variables. None of the interactions were significant. Results are not shown but are available upon request.

\section{Discussion}

Focusing on the fastest growing and largest racial/ethnic minority population in the United States, this study investigated the current smoking status and quitting smoking behaviors among three major Latino adult populations - Mexican Americans, Puerto Ricans, and Cuban Americans - as well as an all-encompassing category called Other Latinos. It was tested whether social capital - measured at the family and neighborhood levels - acted as protective factors against smoking behaviors. The current findings add to a small but growing number of studies on the relationship between social capital and smoking behaviors.

\section{Social capital and smoking behaviors}

Although the overall smoking prevalence among Latino populations was estimated to be approximately $20 \%$, there was considerable variation between the Latino ethnic groups included in this study. The highest prevalence was observed among Puerto Ricans (30.7\%) and the lowest among Mexican Americans (18.1\%). Consistent with these rates, it is interesting to note that the highest prevalence of quitting smoking was found among Mexican Americans (59.3\%) and the lowest among Puerto Ricans (46.5\%).

With regard to the relationship between social capital indicators and smoking behaviors, this study found that neighborhood cohesion was inversely associated with being a current smoker for Mexican Americans only, and with increased odds of quitting for Mexican and Cuban Americans. Although these findings are consistent with prior studies that have identified increased trust in neighbors $^{19}$ and neighborhoods with higher levels of perceived social cohesion ${ }^{32}$ as protective factors against smoking, it is not clear why neighborhood cohesion was not significantly associated with smoking behaviors with the other Latino groups and even with the decreased odds of quitting among Puerto Ricans. It is possible that social norms and cultural expectations in a cohesive neighborhood may exert more control against smoking and generate greater facilitation of quitting among some populations (ie, Mexican Americans) while potentially discouraging quitting among others (ie, Puerto Ricans). One likely reason may be related to the processes of social and economic interactions of the different ethnic groups. Puerto Ricans measure the highest of the Latino populations with regard to family cultural conflict which has been arguably linked to (1) the stress of the industrial decline, and (2) their high rates of marital breakdowns. ${ }^{33}$ This may account for settling patterns within the various Latino communities, resulting in stronger cohesive neighborhoods for Cuban Americans and Mexican Americans, but perhaps not so for Puerto Ricans and Other Latinos. Hence the mechanisms and cultural landscape of neighborhoods may exhibit qualitative differences between the different Latino populations, and have differing effects on smoking habits.

On the basis of prior research that cohesive relationships among Latino families might protect individuals from smoking, ${ }^{34}$ it was expected that family support and family cohesion would be associated with less current smoking and higher odds of quitting smoking, while family conflict would be associated with increased odds of current smoking. Inconsistent with these expectations, it was found that social capital attributable to family was not significantly related to either current smoking or quitting smoking among the Latino American populations, except for Cuban Americans where family cultural conflict was associated with increased odds of current smoking. Although this finding seems unusual, some scholars have noted elsewhere that Cuban Americans tend to report higher scores on family pride and cohesion when compared to other Latino groups. ${ }^{33}$ Thus, when considered with the findings from the current study, smoking may be used as a coping skill to deal with the stress of managing the dissonance between individual (conflict) and sociocultural realities (emphasis on family cohesion). In other words, Cuban Americans have strong social networks and deviating from the norms of that group may result in coping mechanisms, such as smoking; however, if indeed smoking is a coping mechanism among Cuban Americans, this health-damaging coping style needs to be discouraged. Also of interest is the finding that friend support was positively associated with quitting among Puerto Ricans, but not among the other Latino groups. This latter finding may also be due to the unique migration and work patterns of Puerto Ricans 
who may rely more on friend networks than families as the latter might be more separated over time as a result of changing work structures.

\section{Study limitations}

The results of this study should be interpreted with the following limitations in mind. First, the cross-sectional study design necessarily limits making any conclusions about causality between family and neighborhood relationships and smoking behaviors. Second, the measurement of neighborhood social cohesion was based on individual perceptions and was not aggregated to the neighborhood level because of data restriction. However, individual perception of neighborhood social cohesion is considered an important measure of neighborhood context and has been previously shown to be associated with health outcomes. ${ }^{32}$ In addition, this study did not measure some other important aspects of social capital, such as civic engagement and organizational membership, which has been shown to be related with health behaviors in the literature. Third, the NLAAS does not ask questions to assess the extent to which individuals may be addicted to cigarettes. Some of the findings in this study may be influenced by the extent to which individuals are addicted to smoking or at least to differences in the total number of cigarettes they may have smoked over their lives and currently smoke. Future research is needed to understand how various aspects of social capital may be associated with being addicted to smoking or attempting to quit if addicted among the various Hispanic populations. Fourth, the measurement of the variable "quitting smoking" presents some problems. Because individuals classified as having quit smoking include not only those who recently quit but also those who quit at any time in the past, and also because only current levels of social capital would be expected to affect those smokers who have quit recently, the associations found in the study may be less accurate. The preferred approach would be to directly measure the effect of social capital on individuals who recently quit smoking among smokers. ${ }^{35}$ Certainly, future research is needed to examine these associations prospectively.

Notwithstanding these limitations, the present study has several strengths. First, this study used a national sample surveyed in a culturally and linguistically appropriate way, allowing the findings to be generalizable to the United States Latino populations. Second, the social capital theoretical framework used in this study tests a general model of smoking and quitting smoking behaviors among the fastest growing Latino American populations, expanding the utility of the concept beyond its previous use in the general population and enriching the field's understanding of smoking behavior among Latino populations.

\section{Conclusion}

This study examined the relationship between multiple indicators of social capital attributable to family and neighborhood and smoking behaviors across four Latino ethnic groups. The findings suggest that the effects of social capital are context-dependent, varying by ethnicity, and by lumping the diverse Latino American populations into a monolithic group may well likely miss important intragroup differences. In addition, the finding that neighborhood social cohesion is consistently associated with lower odds of current smoking and that there are higher odds of quitting smoking among the Mexican American population suggest a potential tool for smoking prevention and cessation efforts with this population.

\section{Acknowledgments}

This publication was partially supported by National Institute for Minority Health and Health Disparities Grant P60 MD000538 and Centers for Disease Control and Prevention REACH United States Program Grant U58DP001022.

\section{Disclosure}

The authors report no conflicts of interest in this work. The study was considered exempt by the Institutional Review Board because it consisted of secondary analyses of deidentified publicly available data. Its contents are solely the responsibility of the authors and do not necessarily represent the official views of the National Institutes of Health and the Centers for Disease Control and Prevention.

\section{References}

1. Centers for Disease Control and Prevention. Smoking-attributable mortality, years of potential life lost, and productivity losses - United States, 2000-2004. MMWR Morb Mortal Wkly Rep. 2008;57(45): 1226-1228.

2. Barbeau EM, Krieger N, Soobader MJ. Working class matters: socioeconomic disadvantage, race/ethnicity, gender, and smoking in NHIS 2000. Am J Public Health. 2004;94(2):269-278.

3. Cokkinides VE, Halpern MT, Barbeau EM, Ward E, Thun MJ. Racial and ethnic disparities in smoking-cessation interventions: analysis of the 2005 National Health Interview Survey. Am J Prev Med. 2008;34(5):404-412.

4. King G, Polednak A, Bendel RB, Vilsaint MC, Nahata SB. Disparities in smoking cessation between African Americans and Whites: 1990-2000. Am J Public Health. 2004;94(11):1965-1971.

5. Trinidad DR, Perez-Stable EJ, White MM, Emery SL, Messer K. A nationwide analysis of US racial/ethnic disparities in smoking behaviors, smoking cessation, and cessation-related factors. Am J Public Health. 2011;101(4):699-706. 
6. Lopez-Quintero C, Crum RM, Neumark YD. Racial/ethnic disparities in report of physician-provided smoking cessation advice: analysis of the 2000 National Health Interview Survey. Am J Public Health. 2006;96(12):2235-2239.

7. Centers for Disease Control and Prevention. Tobacco use among US racial/ethnic minority groups - African Americans, American Indians and Alaska Natives, Asian Americans and Pacific Islanders, Hispanics. A report of the Surgeon General. Executive summary. MMWR Recomm Rep. 1998;47(RR-18):v-xv, 1-16.

8. Luke D, Esmundo E, Bloom Y. Smoke signs: patterns of tobacco billboard advertising in a metropolitan region. Tob control. 2000; 9(1):16-23.

9. Moore DJ, Williams JD, Qualls WJ. Target marketing of tobacco and alcohol-related products to ethnic minority groups in the United States. Ethn Dis. 1996;6(1-2):83-98.

10. Asumda F, Jordan L. Minority youth access to tobacco: a neighborhood analysis of underage tobacco sales. Health Place. 2009;15(1): 140-147.

11. Commission on Social Determinants of Health. Closing the Gap in a Generation: Health Equity Through Action on the Social Determinants of Health. Geneva: World Health Organization; 2008.

12. Lindstrom M. Social capital, political trust and daily smoking and smoking cessation: a population-based study in southern Sweden. Public Health. 2009;123(7):496-501.

13. Kouvonen A, Oksanen T, Vahtera J, et al. Work-place social capital and smoking cessation: the Finnish Public Sector Study. Addiction. 2008;103(11):1857-1865.

14. Moussa K. Smoking and smoking cessation in a health equity perspective in Sweden - an epidemiological study in the adult population [dissertation]. Malmo: Faculty of Medicine, Lund University; 2009.

15. Lundborg P. Social capital and substance use among Swedish adolescents - an explorative study. Soc Sci Med. 2005;61(6): 1151-1158.

16. Poortinga W. Do health behaviors mediate the association between social capital and health? Prev Med. 2006;43(6):488-493.

17. Patterson JM, Eberly LE, Ding Y, Hargreaves M. Associations of smoking prevalence with individual and area level social cohesion. J Epidemiol Community Health. 2004;58(8):692-697.

18. Siahpush M, Borland R, Taylor J, Singh GK, Ansari Z, Serraglio A. The association of smoking with perception of income inequality, relative material well-being, and social capital. Soc Sci Med. 2006; 63(11):2801-2812.

19. Sapag JC, Poblete FC, Eicher C, et al. Tobacco smoking in urban neighborhoods: exploring social capital as a protective factor in Santiago, Chile. Nicotine Tob Res. 2010;12(9):927-936.

20. Li S, Delva J. Does gender moderate associations between social capital and smoking? An Asian American Study. J Health Behav Public Health. 2011;1(1):41-49.
21. Alegria M, Vila D, Woo M, et al. Cultural relevance and equivalence in the NLAAS instrument: integrating etic and emic in the development of cross-cultural measures for a psychiatric epidemiology and services study of Latinos. Int J Methods Psychiatr Res. 2004;13(4):270-288.

22. Heeringa SG, Wagner J, Torres M, Duan N, Adams T, Berglund P. Sample designs and sampling methods for the Collaborative Psychiatric Epidemiology Studies (CPES). Int J Methods Psychiatr Res. 2004;13(4): 221-240.

23. Putnam RD. Tuning in, tuning out: the strange disappearance of social capital in America. PS Polit Sci Polit. 1995;28(4):664-683.

24. Helliwell JF, Putnam RD. The social context of well-being. Philos Trans R Soc Lond B Biol Sci. 2004;359(1449):1435-1446.

25. Cervantes RC, Padilla AM, Salgado de Snyder N. The Hispanic Stress Inventory: a culturally relevant approach to psychosocial assessment. Psychol Assess. 1991;3(3):438-447.

26. Fukuyama F. Social capital. In: Peterson GB, editor. The Tanner Lectures on Human Values, Volume 19. Salt Lake City: University of Utah Press; 1997:375-484.

27. Mulvaney-Day NE, Alegria M, Sribney W. Social cohesion, social support, and health among Latinos in the United States. Soc Sci Med. 2007;64(2):477-495.

28. Zhang W, Ta VM. Social connections, immigration-related factors, and self-rated physical and mental health among Asian Americans. Soc Sci Med. 2009;68(12):2104-2112.

29. Gee GC, Delva J, Takeuchi DT. Relationships between self-reported unfair treatment and prescription medication use, illicit drug use, and alcohol dependence among Filipino Americans. Am J Public Health. 2007;97(5):933-940.

30. Williams DR, Yu Y, Jackson J, Anderson N. Racial differences in physical and mental health. J Health Psychol. 1997;2(3):335-351.

31. Kish L. Survey Sampling. New York: John Wiley \& Sons; 1965.

32. Kandula NR, Wen M, Jacobs EA, Lauderdale DS. Association between neighborhood context and smoking prevalence among Asian Americans. Am J Public Health. 2009;99(5):885-892.

33. Guarnaccia PJ, Pincay IM, Alegria M, Shrout P, Lewis-Fernandez R, Canino G. Assessing diversity among Latinos: results from the NLAAS. Hisp J Behav Sci. 2007;29(4):510-534.

34. Coonrod D, Balcazar H, Brady J, Garcia S, Van Tine M. Smoking, acculturation and family cohesion in Mexican-American women. Ethn Dis. 1999;9(3):434-440.

35. Brown TT, Scheffler RM, Seo S, Reed M. The empirical relationship between community social capital and the demand for cigarettes. Health Econ. 2006;15(11):1159-1172.
Substance Abuse and Rehabilitation

\section{Publish your work in this journal}

Substance Abuse and Rehabilitation is an international, peer-reviewed, open access journal publishing original research, case reports, editorials, reviews and commentaries on all areas of addiction and substance abuse and options for treatment and rehabilitation. The manuscript management system is completely online and includes a very quick and fair

\section{Dovepress}

peer-review system. Visit http://www.dovepress.com/testimonials.php to read real quotes from published authors. 